\title{
Comparison of the effect of palm with foot reflexology massage on pain intensity in patients after cholecystectomy and appendectomy
} \author{
Azizi $^{5}$,(iD) \\ 1 Medical-Surgical Department, School of Nursing and Midwifery, Zabol University of Medical Sciences, Zabol, Iran \\ 2 Medical-Surgical Nursing, School of Nursing and Midwifery, Mashhad University of Medical Sciences, Mashhad, Iran \\ 3 Akbar Hospital, Mashhad University of Medical Sciences, Mashhad, Iran \\ 4 School of Nursing and Midwifery, Zahedan University of Medical Sciences, Zahedan, Iran \\ 5 Department of Chinese and complementary Medicine, Mashhad University of Medical Sciences, Mashhad, Iran
}

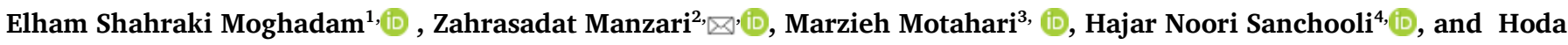

Purpose: This study aimed to compare the effect of reflexology massage of the soles on feet and hands on the intensity of pain in patients after cholecystectomy and appendectomy in women. Methods: This study was a clinical trial pre-test-post-test design with three groups of women who underwent cholecystectomy an appendectomy in Mashhad, Iran. Pain intensity was assessed 1, 4, 12, and 24 hours after the intervention. The intervention was performed within the first hour and 12 hours after surgery for $10 \mathrm{~min}$ for each hand or foot. The control group only received routine interventions. One way ANOVA with Tukey's post hoc test was used to analyze the mean difference in the groups. The significance level was set at $<0.05$. Results: Before the intervention, there was no statistically significant difference amongst the mean pain intensity in the three groups $(p=0.628)$. However, a significant difference was found between the mean of pain intensity amongst the groups $(p<0.001)$. The mean of pain intensity was significantly lower in foot reflexology massage compared to the hand reflexology massage and the control group ( $p<0.05$ ). Conclusion: The results showed that both types of reflexology massage of the palms and soles are effective in reducing pain in the patients after cholecystectomy and appendectomy.

Keywords: Appendectomy, Cholecystectomy, Iran, Surgery, Pain, reflexology

$\triangle$ Corresponding: manzariz@mums.ac.ir; Received: October 14, 2020; Accepted: November 9, 2020; Published: January 1, 2021; This article is available from: https://www.jnexp.ir.

\section{Introduction}

Pain is one of the most common clinical problems of patients after abdominal surgery, which has adverse effects on the respiratory, cardiovascular, gastrointestinal, endocrine, and immune systems (1). Severe pain stimulates the stress response and severely affects the heart and immune system and increases muscle contraction and the need for oxygen. In response to stress, also, blood viscosity and platelet adhesion increase, which leads to increasing the risk of thromboembolism and pulmonary embolism (2). The other disadvantages of postoperative pain are increasing treatment costs, fear, anxiety, anger, resentment, dissatisfaction, prolonged hospital stay, and inappropriate communication between patient and nurse and physician (3). Therefore, effective pain relief has a significant impact on the patient's recovery (4). Different methods apply to manage postoperative pain. One way is the use of systemic opioids, which have several side effects such as respiratory and cardiac suppression (5). Therefore, there is still a lack of more affordable and cost-effective methods for managing postoperative pain. 
Reflexology is one of the non-pharmacological, complementary and manual methods of pain relief. The philosophy of reflexology is to use a unique tactile or pressure technique on the reflection points on the palms and soles to create bio-physiological changes in the body. Reflexology relaxes the muscles and relieves pain through increasing blood flow (6).

Although various studies on reflexology have been performed on chronic pain, there is a few studies have discussed postoperative pain management in abdominal surgery. Therefore, in this study, we investigated the effect of reflexology massage on patients' pain after cholecystectomy and appendectomy.

\section{Methods}

\section{Ethical approval}

The ethical consideration of the study was approved at Mashhad University of Medical Sciences by the ethical committee of biomedical research.

\section{Study design/Setting}

This pre-test-post-test clinical trial was conducted in hospitals of Mashhad, Iran.

\section{Participants}

Ninety women undergoing cholecystectomy and appendectomy were recruited and randomized in three groups as palm reflexology massage, plantar reflexology massage and control. The sample size was estimated after a pilot study on 30 patients (10 individual per group). Eligible samples were randomly assigned to the three groups. The inclusion criteria were women, aged 18-65, elective cholecystectomy or open appendectomy, no history of surgery, no sensory-motor disorders in the hands and feet especially, on the soles and palms, no chronic pain, insensitivity to massage, no deep vein thrombosis, and no addiction, and severe postoperative complications such as heavy bleeding.

\section{Data measurement/ collection}

The instruments used in this study included a demographic questionnaire and the Visual Analog Scale for pain intensity. The researchers evaluated and documented patients' pain intensity one hour after the arrival of the surgical wards from the operating rooms. Then, in the experimental groups, the intervention was performed by the researcher twice in one hour and 12 hours after the operation. For hand massage according to the reflexology protocol, the massage was started from the left wrist area and then the back of the hand, each finger and then the palm. The right hand was massaged in the same way after that. In the foot massage group, it started for the sole of the left foot and was followed as massage of the sole middle area, lateral areas, outer surfaces, and dorsum, then the massage of the right foot was done in the same order. The reflexology massage was performed on each hand and foot for 10 minutes. Pain intensity was evaluated and recorded before and after 1, 4, 12, and 24 hours of the first massage. In addition, the instruments were completed with the help of a research assistant. For consistency of scores, the researcher and the research assistant assessed pain intensity of a group of 5 patients, then the correlation between them was determined.

\section{Analyses}

The data were analyzed using SPSS 22 (IBM Co., Armonk, NY, USA). The demographics were analyzed using descriptive statistics including frequency table and Mean and standard deviation. The reflexology data were analyzed using Analysis of Variance (ANOVA) with Tukey' HSD post-hoc test. The significance level was set $<0.05$.

\section{Results}

Demographic data of this study showed that the mean age of patients was $35.46(\mathrm{SD}=16.6)$, and most of them 
$(52.2 \%, \mathrm{n}=47)$ were married, $27.7 \%$ had a diploma, and $57.7 \%$ underwent cholecystectomy [Table 1].

Table 2 shows that the mean pain intensity in the three groups was not statistically significant before the intervention ( $p=0.978)$. However, the trend shows a significant difference in the mean pain intensity among the three groups after interventions $(p<0.001)$.

\section{Table1. Demographic profile of patients}

\begin{tabular}{llll}
\hline $\begin{array}{l}\text { Group } \\
\text { Variable }\end{array}$ & $\begin{array}{l}\text { Hand } \\
\mathbf{n}(\%)\end{array}$ & $\begin{array}{l}\text { Foot } \\
\mathbf{n}(\%)\end{array}$ & $\begin{array}{l}\text { Control } \\
\mathbf{n}(\%)\end{array}$ \\
\hline $\begin{array}{l}\text { Type of surgery } \\
\text { Cholecystectomy }\end{array}$ & $18(60)$ & $19(63.3)$ & $15(50)$ \\
Appendectomy & $12(40)$ & $11(36.7)$ & $15(50)$ \\
Marriage status & & & \\
Single & $8(26.7)$ & $10(33.3)$ & $12(40)$ \\
Married & $17(56.7)$ & $14(46.7)$ & $16(53)$. \\
Widow & $5(16.7)$ & $6(20)$ & $2(6.7)$ \\
Education level & & & \\
Illiterate & $8(26.7)$ & $3(10)$ & $1(3.3)$ \\
Primary school & $5(16.7)$ & $6(20)$ & $3(10)$ \\
Secondary & $5(16.7)$ & $6(20)$ & $11(36.7)$ \\
High School & $8(26.7)$ & $9(30)$ & $8(26.7)$ \\
Academic & $4(13.3)$ & $6(20)$ & $7(23.3)$ \\
Age (yr), Mean (SD) & $36.9(19.2)$ & $36.3(16)$ & $33.06(14.5)$ \\
\hline
\end{tabular}

$\mathrm{n}$, Number; SD, Standard deviation

Table 2 Mean and standard deviation of pain intensity among the three groups of patients

\begin{tabular}{llllll}
\hline $\begin{array}{l}\text { Group } \\
\begin{array}{l}\text { Ses- } \\
\text { sions }\end{array}\end{array}$ & \multicolumn{4}{l}{ Pain intensity (Mean (SD)) } & F; $p$ - value \\
Hand & Foot & $\begin{array}{l}\text { Con- } \\
\text { trol }\end{array}$ & & \\
\hline Base- & 8.66 & 8.7 & 8.63 & $\mathrm{~F}(2,87)=0.02 ;$ & \\
line & $(1.09)$ & $(1.6)$ & $(1.15)$ & $P=0.978$ & \\
$\mathbf{1}$ & ${ }^{\mathrm{a}} 6.93$ & ${ }^{\mathrm{a}, \mathrm{b}} 6.03$ & 8.66 & $\mathrm{~F}(2,87)=20.04 ;$ & $P$ \\
& $(1.46)$ & $(1.80)$ & $(1.15)$ & $<0.001$ & \\
$\mathbf{2}$ & ${ }^{\mathrm{a}} 5.53$ & $\mathrm{a}, \mathrm{b} 4.06$ & 7.16 & $\mathrm{~F}(2,87)=21.18 ;$ & $P$ \\
& $(1.92)$ & $(1.96)$ & $(1.64)$ & $<0.001$ & \\
$\mathbf{3}$ & ${ }^{\mathrm{a}} 3.96$ & $\mathrm{a}, \mathrm{b} 2.43$ & 4.93 & $\mathrm{~F}(2,87)=21.18 ;$ & $P$ \\
& $(2.45)$ & $(1.43)$ & $(1.04)$ & $<0.001$ & \\
$\mathbf{4}$ & 2.36 & $\mathrm{a}$ a,b 1.16 & 2.15 & $\mathrm{~F}(2,87)=21.18 ;$ & $P$ \\
& $(2.04)$ & $(0.98)$ & $(1.5)$ & $<0.001$ & \\
\hline
\end{tabular}

a different from the control group; $b$ different from hand group; SD, standard deviation
Tukey's HSD post-hoc test showed a significant difference in the means between foot reflexology and control group as well as hand group. However, there was no significant difference in the means between hand reflexology and control group after 24 hours of the first session of intervention.

\section{Discussion}

The present study shows that despite the progressive reduction of pain in the patients of all three groups, i.e., hand reflexology massage, foot reflexology massage, and control. In the experimental groups, i.e., hand and foot reflexology massage the reduction of pain after the intervention was higher compared to the control group. Besides, the foot reflexology was more effective than hand ones. Although the hand and foot reflex zones are relatively similar, it seems that the nerve endings on the feet are more sensitive than the hand's ones. Previous studies have also shown the effects of pain relief using reflexology. Reflexology has a positive impact on reducing pain in patients with chronic low back pain (7), breast cancer (8), appendectomy (9), abdominal and chest surgery (4), and cesarean section (10). Reflexology has also reduced pain and increased the quality of life in rheumatoid arthritis patients (11).

Most studies indicate reflexology is an effective method for alleviating pain.

\section{Limitations}

Of limitation of the current study, the type and dose of used narcotic were dissimilar, which might be affected by the results and generalizability of findings. Despite limitations, reflexology massage is an effective and lowrisk method that can be used as a non-pharmacological and non-invasive intervention in pain control interventions after surgery.

\section{Conclusion}

The results of the present study show that most patients experienced moderate to severe abdominal pain after 
surgery, which indicates a need for attention to patients' pain after surgery. Reflexology can be used for patients after cholecystectomy and appendectomy. Therefore, in general, both types of reflexology massage of the palms and soles are effective in reducing pain, and nurses can use reflexology as a non-pharmacological and complementary method to reduce the severity of pain after surgery.

\section{Author contributions}

Conceptualization: ES, ZM, HA. Formal analysis: ZM. Methodology: ES, ZM, HA. Writing - original draft: ES, HNS. Writing - review \& editing: ZM, HA, ZM.

\section{Conflict of interest}

No declared.

\section{Funding}

None.

\section{Acknowledgments}

None.

\section{References}

[1] Gan TJ. Poorly controlled postoperative pain: prevalence, consequences, and prevention. J Pain Res. 2017 Sep 25;10:22872298. doi: $10.2147 /$ JPR.S144066.

[2] American Psychological Association. 2018, Nov 1. Stress effects on the body. http://www.apa.org/topics/stress-body.

[3] Carpenito-Moyet, Lynda Juall, ed. Nursing diagnosis: Application to clinical practice. Lippincott Williams \& Wilkins, 2016.

[4] Mohammad Aliha J, Behroozi N, Peyrovi H, Mehran A. The effect of foot reflexology massage on incisional pain in abdominal and chest surgery patients admitted to intensive care unit. Cardiovasc Nurs J 2013; 2(2):6-12. http://journal.icns.org.ir/article-1-172-en.html
[5] US Department of Health and Human Services. Pain management best practices Inter-Agency Task force report: updates, gaps, inconsistencies, and recommendations. Washington, DC: US Department of Health and Human Services 2019.

[6] Embong NH, Soh YC, Ming LC, Wong TW. Revisiting reflexology: Concept, evidence, current practice, and practitioner training. J Tradit Complement Med 2015 Sep 28;5(4):197-206. doi: 10.1016/j.jtcme.2015.08.008.

[7] Babadi ME, Nazari F, Safari R, Abdoli S. The effect of reflexology on pain perception aspects in nurses with chronic low back pain in Isfahan. Iran J Nurs Midwifery Res 2016 SepOct;21(5):487-492. doi: 10.4103/1735-9066.193395.

[8] Luo Z, Wang L, Sikorskii A, Wyatt G. Healthcare service utilization and work-related productivity in reflexology intervention for advanced breast cancer women. Support Care Cancer 2019 Aug;27(8):2837-2847. doi: 10.1007/s00520-018-4592-4.

[9] Taheri H, Naseri-Salahshour V, Abedi A, Sajadi M. Comparing the Effect of Foot and Hand Reflexology on Pain Severity after Appendectomy: A Randomized Clinical Trial. Iran J Nurs Midwifery Res 2019 Nov 7;24(6):451-456. doi: 10.4103/ijnmr.IJNMR_85_18.

[10] Khoshtarash M, Ghanbari A, Yegane MR, Kazemnejhad E, Rezasoltani P. Effects of foot reflexology on pain and physiological parameters after cesarean section. Koomesh 2012 Sep 10;14(1):109-16.

[11] Metin ZG, Ozdemir L. The effects of aromatherapy massage and reflexology on pain and fatigue in patients with rheumatoid arthritis: a randomized controlled trial. Pain Manag Nurs 2016 Apr 1;17(2):140-9.

“Cite: Shahraki Moghadam E, Manzari Z, Motahari M, Noori Sanchooli H, Azizi $\mathrm{H}$. Comparison of the effect of palm with foot reflexology massage on pain intensity in patients after cholecystectomy and appendectomy. J Nurs Explor 2021 Jan;1(1):7. doi: 10.29252/jnexp.1.1.7 